\title{
Sleep-disordered breathing and stroke: is there a rationale for treatment?
}

\author{
O. Parra
}

The association between sleep-disordered breathing (SDB) and stroke cannot be attributed to chance. Indeed, if a link between SDB and cardiovascular disease were demonstrated [1-5], the absence of a relationship with stroke would be surprising. Although we still lack definitive and consistent data from large epidemiological surveys, multiple studies using a variety of methodologies have shown a high prevalence of SDB following stroke, especially obstructive sleep apnoea (OSA) [6-13]. This prevalence is greater than expected, bearing in mind the available epidemiological data $[14,15]$. Nevertheless, these data must be interpreted with caution since stroke patients have a high mean age and the number of obstructive events increases with age, without clinical relevance [16, 17]. Moreover, case-control studies have also demonstrated a significantly higher prevalence of SDB in patients with stroke than in controls $[8,9,11]$.

SDB may be regarded as a consequence (mainly central events) $[18,19]$ or as a cause (mainly obstructive events) [13] of stroke. Given the availability of an effective and safe treatment for OSA [20-24], nasal continuous positive airway pressure (nCPAP) could modify the incidence of stroke (if SDB is regarded as a risk factor) or the outcome of these patients (if SDB is considered as a prognostic factor). In this issue, WESSENDORF et al. [25] and SANDBERG et al. [26] have endeavoured to treat stroke and SDB patients with nCPAP. The resulting data are the first to show a beneficial effect of this treatment in these patients, thereby suggesting the feasibility of introducing nCPAP in such patients, in whom cognitive impairment and physical disability may constitute important drawbacks, and in whom excessive daytime sleepiness does not always justify treatment [27]. Despite concerns about some of the methods used, both papers are encouraging.

In support of the idea that SDB is a risk factor for stroke, we have a number of case-control studies previously referred to $[8,9,11]$, as well as a number of physiopathological mechanisms that could be involved. One such mechanism could be hypertension, known as the most prevalent and modifiable risk

Sleep Unit, Pneumology, Hospital del Sagrat Cor., University of Barcelona, Barcelona, Spain.

Correspondence: O. Parra, Hospital Sagrat Cor., Pneumology Department, C/Viladomat 288, 08029 Barcelona, Spain. Fax: 34934948906 . factor for stroke, and whose treatment substantially reduces the risk [28, 29]. Recently, PePPARD et al. [3] not only demonstrated that SDB is an independent risk factor for hypertension, but also found a doseresponse association. Similar results were obtained using a cross-sectional analysis in the Sleep Health Heart Study [4]. As far as nCPAP seems to exert a positive influence on hypertension when OSA is present [30], a beneficial effect should also be expected in patients with stroke, hypertension and OSA. The paper by WESSENDORF et al. [25] is the first to show that, in patients with stroke, receiving optimal antihypertensive treatment nCPAP is associated with a decrease in nocturnal blood pressure, converting some patients from nondeeper to deeper, at least on a shortterm evaluation. Thus, nCPAP might have therapeutic and prognostic benefits, achieving a better optimization of secondary prophylaxis for stroke through a better control of hypertension. Moreover, in an earlier case report, WESSENDORF et al. [31] described a case of refractory hypertension in a patient with haemorrhagic stroke and OSA, in whom only nCPAP was able to control blood pressure.

A second mechanism that could account for the link between SDB and stroke is based on biological mediators, such as fibrinogen plasma level. Fibrinogen has previously been implicated as a risk factor for myocardial infarction and stroke $[32,33]$. WESSENDORF et al. [34] demonstrated the correlation between the severity of coexisting OSA and fibrinogen plasma level in patients with stroke, suggesting a possible physiopathological mechanism to explain an increased risk for stroke in patients with OSA. Furthermore, CHIN et al. [35] demonstrated a reduction in fibrinogen levels following nCPAP treatment.

A third mechanism could be attributed to the haemodynamic changes in cerebral blood flow (reductions and fluctuations documented by transcranial doppler) occurring during obstructive apnoeas and favouring ischaemia [36, 37]. In addition, cerebrovascular reactivity to hypercapnia is diminished in patients with OSA, which can be corrected with nCPAP treatment, suggesting a reduction in cerebral vasodilator reserve and an increased susceptibility to cerebral ischaemia in patients with OSA [38].

From a prognostic point of view, the relationship between SDB and stroke can be addressed by analysing the outcome of patients in terms of neurological recovery, response to rehabilitation, quality of life, recurrence or mortality. Few reports with a small 
number of patients have evaluated how snoring [39] and SDB adversely affect prognosis in stroke patients. In a noncontrolled study, GooD et al. [10] suggested that SDB in stroke was associated with a poorer functional outcome after 3 and 12 months, and with a higher mortality after $1 \mathrm{yr}$. In a case-control study, DYKEN et al. [9] observed a $21 \%$ mortality at 4 yrs follow-up after stroke, the apnoea/hypopnoea index (AHI) being significantly higher in patients who died. In this regard, we found that AHI is an independent prognostic factor associated with mortality in patients with a first episode of stroke, and moreover, that mortality increases proportionally to AHI [40].

The two papers referred to in this issue $[25,26]$ seek to confirm that nCPAP treatment improves outcome in stroke patients. The authors $[25,26]$ are the first to provide some interesting data on this subject, thereby opening the door to further investigation. However, a number of factors should be borne in mind when interpreting the results. WESSENDORF et al. [25] used standard methods for SDB diagnosis despite performing a subjective and poorly-validated test for analysing neuropsychological or quality of life aspects. SANDBERG et al. [26] used questionable methods for diagnosing SDB and nCPAP titration, although the neuropsychological tests performed provide new and interesting data on the management of these patients.

Both studies have enrolled patients with moderate OSA that were admitted to a rehabilitation unit, i.e. in a stable phase, and have analysed results for a short period. In this setting, WESSENDORF et al. [25] have used a "well-being test", obtaining, by means of a visual analogue scale, significantly more improvement in compliant patients than in noncompliant patients. Despite the positive results, further validated neuropsychological tests or quality of life questionnaires are needed to yield more consistent data. Conversely, as demonstrated by SANDBERG et al. [26], depression symptoms improve significantly in patients with nCPAP. This finding is very relevant because deficiencies in attention and concentration and increased tiredness, classically attributed to cognitive and physical dysfunction caused by stroke or poststroke depression, could in fact be caused by SDB. Moreover, it is well known that depression exerts a negative influence on motor rehabilitation and re-establishment [41-43], thus increasing mortality [44]. Therefore, these results could also have prognostic and therapeutic implications.

A number of problems could be encountered in acceptance and compliance of nCPAP in this setting: old age, low subjective sleepiness, functional disability, cognitive deficits, central apnoeas detected early after stroke, facial palsy as a cause of mouth leak, etc. WESSENDORF et al. [25] demonstrate a good primary acceptance and compliance, i.e. $\sim 70 \%$, which is similar to that obtained in OSA patients without stroke [45]. SANDBERG et al. [26] achieve a lower compliance $(50 \%)$ with older patients. Poor compliance is associated with aphasia and a poor Barthel Index [25], as well as with delirium, depression and a lower cognitive level [26]. There is no doubt, these data are better than expected for these patients, although probably not achieved without special coaching [46]. However, it should borne in mind that the authors refer to primary acceptance, whereas long-term compliance remains uncertain.

One concern is choosing the moment for commencing nCPAP treatment, especially bearing in mind that recurrent hypoxaemia and flow cerebral fluctuations due to apnoea could damage the area of ischaemic penumbra and therefore, affect prognosis. In this case, nCPAP could exert a beneficial influence in the acute phase, although this remains to be confirmed. Moreover, compliance could constitute a greater problem in this setting. Another possible argument in favour of treatment is to prevent stroke recurrence, which is an important cause of mortality in these patients [47]. Often, one or more transient ischaemic attacks (TIA) precede stroke [28]. Patients with TIA could constitute the most important target for diagnosis and treatment, since it would be possible to perform a primary prophylaxis in presumably younger and more compliant patients.

Data available, to date, highlight the following considerations. Key questions should be included into the routine anamnesis of patients with transient ischaemic attack or stroke to be considered for treatment if obstructive sleep apnoea is confirmed. The current issue contains some original and encouraging data that could yield a greater insight into this subject. Nevertheless, further long-term studies are needed in order to determine the priority of treatment, the specific effects to be expected, and the manner in which compliance could limit such expectations.

\section{References}

1. Hung J, Whitford EG, Pearsons RW, Hillman DR. Association of sleep apnoea with myocardial infarction in men. Lancet 1990; 336: 251-264.

2. Peker Y, Hedner J, Kraiczi H, Loth S. Respiratory disturbance index. An independent predictor of mortality in coronary artery disease. Am J Respir Crit Care Med 2000; 162: 81-86.

3. Peppard PE, Young T, Palta M, Skatrud J. Prospective study of the association between sleep-disordered breathing and hypertension. N Engl J Med 2000; 342: 378-384.

4. Nieto FJ, Young TB, Lind BK, et al. Association of sleep-disordered breathing, sleep apnea and hypertension in a large community-based study. Sleep Heart Health Study. JAMA 2000; 283: 1824-1836.

5. Lavie P, Herer P, Hoffstein V. Obstructive sleep apnoea syndrome as a risk factor for hypertension: population study. BMJ 2000; 320: 479-482.

6. Palomäki H, Partinen M, Juvela S, Kaste M. Snoring and the risk of ischemic brain infarction. Stroke 1991; 22: 1021-1025.

7. Kapen S, Park A, Goldberg J, Whynter J. The incidence and severity of obstructive sleep apnea in ischaemic cerebrovascular disease. Neurology 1991; 41: Suppl. 1, 125.

8. Mohsenin V, Valor R. Sleep apnea in patients with hemispheric stroke. Arch Phys Med Rehabil 1995; 76: 71-76.

9. Dyken ME, Somers VK, Yamada T, Ren ZY, Zimmerman MB. Investigating the relationship 
between stroke and obstructive sleep apnea. Stroke 1996; 27: 401-407.

10. Good DC, Henkle JQ, Geller D, Welsh J, Verhulst S. Sleep disordered breathing and poor functional outcome after stroke. Stroke 1996; 27: 252-259.

11. Basseti C, Aldrich MS, Chervin RD, Quint D. Sleep apnea in patients with transient ischaemic attack and stroke. Neurology 1996; 47: 1167-1173.

12. Bassetti C, Aldrich MS. Sleep apnea in acute cerebrovascular disease: final report in 128 patients. Sleep 1999; 22: 217-223.

13. Parra O, Arboix A, Bechich S, et al. Time course of sleep-related breathing disorders in first-ever stroke or transient ischaemic attack. Am J Respir Crit Care Med 2000; 161: 375-380.

14. Young T, Palta M, Dempsey J, Skatrud J, Weber S, Badr S. The occurrence of sleep-disordered breathing among middle-aged adults. $N$ Engl J Med 1993; 328: 1230-1235.

15. Durán J, Esnaola S, Rubio R, Iztueta A. Obstructive sleep apnea-hypopnea and related clinical features in a population-based sample of subjects aged 30 to 70 years. Am J Respir Crit Care Med 2001; 163: 685-689.

16. Ancoli-Israel S, Klauber MR, Kripke DF, Mason W, Fell R, Kaplan O. Sleep disordered breathing in community-dwelling elderly. Sleep 1991; 14: 486-495.

17. Bixler EO, Vgontzas AN, Ten Have T, Tyson K, Kales A. Effects of age on sleep apnea in men I: prevalence and severity. Am J Respir Crit Care Med 1998; 157: 144-148.

18. Levin BE, Margolis G. Respiration secondary to a unilateral brain stem infarction. Ann Neurol 1977; 1: 583-586.

19. Askenasy JM, Goldhamer I. Sleep apnea as a feature of bulbar stroke. Stroke 1988; 19: 637-639.

20. Engleman HM, Martin SE, Kingshott RN, Mackay T, Deary IJ, Douglas NJ. Randomised placebo controlled trial of daytime function after continuous positive pressure (CPAP) therapy for sleep apnoea/ hypopnoea syndrome. Thorax 1998; 53: 341-345.

21. Jenkinson C, Davies RJO, Mullins R, Stradling JR. Comparison of therapeutic and subtherapeutic nasal continuous positive airway pressure for obstructive sleep apnoea: a randomised prospective parallel trial. Lancet 1999; 353: 2100-2105.

22. Engleman HM, Kingshott RN, Wraith PK, Mackay TW, Deary IJ, Douglas NJ. Randomized placebocontrolled crossover trial of daytime function after continuous positive pressure for mild sleep apnea/ hypopnea syndrome. Am J Respir Crit Care Med 1999; 159: 461-467.

23. Davies RJO, Stradling JR. The efficacy of nasal continuous positive airway pressure in the treatment of obstructive sleep apnea syndrome is proven. $A m$ J Respir Crit Care Med 2000; 161: 1775-1776.

24. Montserrat JM, Ferrer M, Hernandez L, et al. Effectiveness of CPAP treatment on daytime function in sleep apnea syndrome. A randomized controlled study with an optimized placebo. Am J Respir Crit Care Med 2001; 164: 1-6.

25. Wessendorf TE, Wang Y-M, Thilmann AF, Sorgenfrei U, Konietzko N, Teschler H. Treatment of obstructive sleep apnoea with nasal continuous positive airway pressure in stroke. Eur Respir $J$ 2001; 18: 623-629.

26. Sandberg O, Franklin KA, Bucht G, Eriksson S, Gustafson Y. Nasal continuous positive airway pressure in stroke patients with sleep apnoea: a randomized treatment study. Eur Respir J 2001; 18: 630-634.

27. Chervin R, Aldrich MS. The Epworth Sleepiness Scale may not reflect objective measures of sleepiness or sleep apneas. Neurology 1999; 52: 125-131.

28. Arboix A, Morcillo C, García-Eroles L, Oliveres M, Massons J, Targa C. Different vascular risk factors profiles in ischaemic stroke subtypes: study from the "Sagrat Cor Hospital of Barcelona Stroke Registry". Acta Neurol Scand 2000; 102: 264-270.

29. Gorelick PB, Sacco RL, Smith DB, et al. Prevention of a first stroke: a review of guidelines and a multidisciplinary consensus statement from The National Stroke Association. JAMA 1999; 281: 1112-1120.

30. Dimsdale JE, Loredo JS, Profant J. Effects of nasal CPAP on blood pressure: a placebo trial. Hypertension 2000; 35: 144-147.

31. Wessendorf TE, Tescheler H, Wang YM, Sorgenfrei U, Thilmann A. Obstructive sleep apnoea syndrome. A probable cause of the refractory hypertension in intracerebral haemorrhage. Nervenarzt 1999; 70: 927 930.

32. Di Minno G, Mancini M. Measuring plasma fibrinogen to predict stroke and myocardial infarction. Arteriosclerosis 1990; 10: 1-7.

33. Resch KL, Ernst E, Matrai A, Paulsen HF. Fibrinogen and viscosity as risk factors for subsequent cardiovascular events in stroke survivors. Ann Intern Med 1992; 117: 371-375.

34. Wessendorf TE, Thilmann AF, Wang YM, Schreiber A, Konietzko N, Teschler H. Fibrinogen levels and obstructive sleep apnea in ischemic stroke. Am J Respir Crit Care Med 2000; 162: 2039-2042.

35. Chin $\mathrm{K}$, Ohi $\mathrm{M}$, Kita $\mathrm{H}$, et al. Effects of nCPAP therapy on fibrinogen levels in obstructive sleep apnea syndrome. Am J Respir Crit Care Med 1996; 153: 1972-1976.

36. Balförs EM, Franklin K. Impairment of cerebral perfusion during obstructive sleep apneas. Am J Respir Crit Care Med 1994; 150: 1587-1591.

37. Netzer N, Werner P, Jochums I, Lehmann M, Strohl $\mathrm{K}$. Blood flow of the middle cerebral artery with sleepdisordered breathing. Stroke 1998; 29: 87-93.

38. Diomedi M, Placidi F, Cupini LM, Bernardi G, Silvestrini M. Cerebral hemodynamic changes in sleep apnea syndrome and effect of continuous positive airway pressure treatment. Neurology 1998; 51: 10511056.

39. Sprigs DA, French JM, Murdy JM, Curless RH, Bates $\mathrm{D}$, James OFW. Snoring increases the risk of stroke and adversely affects prognosis. $Q J$ Med 1992; 84: 555-562.

40. Parra O, Arboix A, Bechich S, et al. Influencia de los Trastornos Respiratorios del Sueño (TRS) sobre la supervivencia de pacientes con primer episodio de Ictus o Accidente Isquémico Transitorio (AIT). Arch Bronconeumol 2000; 36: S8.

41. Parikh RM, Robimson RG, Lipsey JR, Starkstein SE, Fedoroff JP, Price TR. The impact of post-stroke depression on recovery in activities of daily living over a 2-year follow-up. Arch Neurol 1990; 47: 785-789.

42. Morris LP, Raphael B, Robinson RG. Clinical depression is associated with impaired recovery from stroke. Med J Aust 1992; 157: 239-242.

43. Carson AJ, MacHale S, Allen K, et al. Depression after stroke and lesion location: a systemic review. Lancet 2000; 356: 122-126. 
44. Morris PLP, Robinson RG, Andrzejewski P, Samuels J, Price TR. Association of depression with 10-year post-stroke mortality. Am J Psychiatry 1993; 150: 124-129.

45. Peters T, Collard P, Aubert G, Dury M, Delguste P, Rodenstein DO. Acceptance and long-term compliance with nCPAP in patients with obstructive sleep apnoea syndrome. Eur Respir J 1996; 9: 939944.
46. Hoy CJ, Vennelle M, Kingshott RN, Engleman HM, Douglas NJ. Can intensive support improve continuous positive airway pressure use in patients with sleep apnea/hypopnea syndrome? Am J Respir Crit Care Med 1999; 159: 1096-1100.

47. Bogousslavsky J, Brott T, Diener HC, et al. Optimizing Intensive Care in Stroke: A European Perspective. A Report of an $\mathrm{Ad} \mathrm{Hoc} \mathrm{Consensus} \mathrm{Group} \mathrm{Meeting.}$ Cerebrovasc Dis 1997; 7: 113-128. 